Marquette University

e-Publications@Marquette

Nursing Faculty Research and Publications

Nursing, College of

5-1-2016

Describing Pediatric Hospital Discharge Planning Care Processes Using the Omaha System

Diane E. Holland

Mayo Clinic

Catherine E. Vanderboom

Mayo Clinic

Adriana M. Delgado

Mayo Clinic

Marianne E. Weiss

Marquette University, marianne.weiss@marquette.edu

Karen A. Monsen

University of Minnesota - Twin Cities

Accepted version. Applied Nursing Research, Vol. 30 (May 2016): 24-28. DOI. (C) 2015 Elsevier Inc. Used with permission. 


\title{
Describing Pediatric Hospital Discharge Planning Care Processes Using the Omaha System
}

\author{
Diane E. Holland \\ Division of Nursing Research, Mayo Clinic, \\ Rochester, $M N$ \\ Catherine E. Vanderboom \\ Division of Nursing Research, Mayo Clinic, \\ Rochester, $M N$ \\ Adriana M. Delgado \\ Division of Nursing Research, Mayo Clinic, \\ Rochester, $M N$ \\ Marianne E. Weiss \\ College of Nursing, Marquette University \\ Milwaukee, WI \\ Karen A. Monsen \\ School of Nursing, University of Minnesota, \\ Minneapolis, MN
}

Applied Nursing Research, Vol 30 (May 2016): pg. 24-28. DOI. This article is (C) Elsevier (WB Saunders) and permission has been granted for this version to appear in e-Publications@Marquette. Elsevier (WB Saunders) does not grant permission for this article to be further copied/distributed or hosted elsewhere without the express permission from Elsevier (WB Saunders). 
NOT THE PUBLISHED VERSION; this is the author's final, peer-reviewed manuscript. The published version may be accessed by following the link in the citation at the bottom of the page.

\section{Abstract}

Purpose: Although discharge planning (DP) is recognized as a critical component of hospital care, national initiatives have focused on older adults, with limited focus on pediatric patients. We aimed to describe patient problems and targeted interventions as documented by social workers or DP nurses providing specialized DP services in a children's hospital.

Methods: Text from 67 clinical notes for 28 patients was mapped to a standardized terminology (Omaha System). Data were deductively analyzed. Results: A total of 517 phrases were mapped. Eleven of the 42 Omaha System problems were identified. The most frequent problem was health care supervision $(297 / 517 ; 57.4 \%)$. Three Omaha System intervention categories were used (teaching, guidance, and counseling; case management; and surveillance). Intervention targets are varied by role.

Conclusion: The findings provide a rich description of the nature of DP for complex pediatric patients and increase our understanding of the work of DP staff and the influence of the DP practice model.

\section{Abbreviations}

- DP, discharge planning;

- DPN, discharge planning nurse;

- SW, social worker

Keywords

- Discharge planning;

- Omaha System;

- Pediatrics;

- Standardized terminologies

The discharge planning (DP) process is a critical component of interprofessional hospital care because it serves as the foundation for care transitions across health care settings and providers. When the term discharge planning appears in the literature, the process is generally understood to involve actions and activities of hospital clinicians which are designed to facilitate smooth and safe patient transitions from acute care to subsequent care or home settings. Although DP is a required activity in the United States by hospitals participating in the Centers for Medicare \& Medicaid Services payment programs, there is no universal or widely accepted operational model for the DP process. A wide variation in models of DP care delivery was noted in a recent Cochrane Review ( Shepperd et al., 2013), with differing configurations of roles and activities assigned to steps in the process.

National initiatives related to DP have focused on adults (Mitchell et al., 2015), particularly older adults (Gardner et al., 2014, Hansen et al., 2013 and Naylor, 2014), with limited focus on pediatric

Applied Nursing Research, Vol 30 (May 2016): pg. 24-28. DOI. This article is (C) Elsevier (WB Saunders) and permission has been granted for this version to appear in e-Publications@Marquette. Elsevier (WB Saunders) does not grant permission for this article to be further copied/distributed or hosted elsewhere without the express permission from Elsevier (WB Saunders). 
patients. None of the studies reviewed for the Cochrane Library (Shepperd et al., 2013) included DP for pediatric patients. Recognition is emerging of the need to develop a DP model to address the transitional care needs of families of children with medical complexities (Berry, Agrawal, Cohen, \& Kuo, 2013). These families may have difficulties with access to care and limited resources that place them at risk for adverse outcomes such as readmissions (Berry, Toomey, et al., 2013 and Srivastava and Keren, 2013). To advance the development and testing of DP interventions for pediatric patients, a clear delineation of the actions and activities within a pediatric DP model of care is needed. Without a standardized mechanism for describing the actions and activities involved in providing DP care, it is difficult to demonstrate the unique contributions of the hospital DP process to care transitions from acute care settings, develop frameworks to guide care processes, evaluate outcomes, and establish evidence-based practices.

Standardized terminologies in health information systems provide a mechanism for explicating terms and concepts within clinician documentation to describe not only the primary needs of patient populations, but also which interventions were used to address patient problems. Using a standardized terminology increases the comparability of clinical data across settings and models of care. The Omaha System is one such interprofessional standardized terminology used successfully for more than four decades in diverse settings (Martin, 2005). The Omaha System consists of three components: Problem Classification Scheme, Intervention Scheme, and Problem Rating Scale for Outcomes. The Intervention Scheme consists of standardized terms that may be used for DP interventions addressing patient problems (Martin, 2005).

In the DP literature, three reports have used the Omaha System as a standardized tool to describe patient problems and nurse interventions related to hospital DP (Bowles, 2000b, Brooten et al., 2003 and Naylor et al., 2000). All three studies included DP interventions within the greater context of providing transitional care to adults. Use of the Omaha System enabled classification of the problems, interventions, and their targets across diverse patient populations. 
Although the Omaha System was successfully used to categorize DP problems and interventions for hospitalized adults, no studies have used a standardized terminology to describe DP actions and activities in a children's hospital setting. The purpose of this study was to describe patient problems and DP interventions for hospitalized children, as documented by DP staff in electronic health records. The Omaha System served as the organizing framework for the study.

\section{Methods}

\subsection{Design}

This study was conducted as an exploratory aim within an ongoing study of the effects of early engagement of pediatric DP staff on length of hospital stay and hospital readmissions. Thematic analysis using the Omaha System as the organizing framework was performed on the clinical notes of social workers (SWs) and DP nurses (DPNs) documenting the DP care they provided to pediatric patients and their families. Quantitative analysis comparing problems and interventions between SWs and DPNs augmented the qualitative analysis in the larger study.

\subsection{Sample and setting}

Patient eligibility for the larger study included children ages 1 month to 18 years who were hospitalized for medical or surgical reasons at an 86-bed children's hospital in an academic medical center with Magnet designation. Of 103 patients in the convenience sample for the larger study, 28 patients had one or more DP documentation entries by one of eight SWs or six DPNs. The sample for this analysis consisted of the 67 clinical notes these SWs and DPNs authored when providing specialized DP services to the 28 patients and their families. DP care was provided only by an SW for eight of the patients/families, only by a DPN for 14 patients/families, and by both an SW and a DPN for six patients/families.

The DP model of care at the study site included an interprofessional approach. Initial assessment of the need for specialized DP services and discharge teaching for all patients was the been granted for this version to appear in e-Publications@Marquette. Elsevier (WB Saunders) does not grant permission for this article to be further copied/distributed or hosted elsewhere without the express permission from Elsevier (WB Saunders). 
responsibility of the direct care nursing staff. If the patient's discharge plan was complex and required additional expertise, information, and attention, referrals were made to involve SWs or DPNs who were consistently assigned to the children's hospital. Both roles involved coordination of complex care across settings (Holland \& Hemann, 2011). Specifically, the DPNs were asked to become involved if DP needs were primarily medically based services such as formal home health care services or specialized home-going equipment, oxygen, continuous intravenous medications, or specialized transportation. The SWs were generally consulted if DP needs involved enrollment in waivered programs to pay for services or early childhood intervention programs offered in the community.

\subsection{Omaha system}

The Omaha System is a multi-disciplinary ontology and taxonomy designed to facilitate healthcare practice, documentation, and information management (Martin, 2005). In this study the Problem Classification Scheme and Intervention Scheme were used to identify DP interventions. The Problem Classification Scheme identifies and organizes health care concepts (problems). Within the Omaha System, 42 problems are classified into four domains: environmental (four problems), psychosocial (12 problems), physiological (18 problems), and health-related behaviors (eight problems). Each problem has a unique definition and set of signs/symptoms.

The Intervention Scheme describes healthcare activities used to address the problems. It consists of four defined categories (actions) and 75 associated targets (details of the intervention). One intervention is defined as three linked terms: problem + category + target. Category terms are defined as follows: 1) Surveillance: acquisition, interpretation, and synthesis of data for clinical decision making; 2) teaching, guidance, and counseling: giving information, anticipating problems, encouraging actions and responsibility for self-care and coping, and assisting with decision making and problem solving; 3) case management: care coordination, advocacy, and referrals that facilitate service delivery; and 4) treatments and procedures: technical activities directed toward identifying risk factors and early signs and symptoms, preventing signs

Applied Nursing Research, Vol 30 (May 2016): pg. 24-28. DOI. This article is (C) Elsevier (WB Saunders) and permission has been granted for this version to appear in e-Publications@Marquette. Elsevier (WB Saunders) does not grant permission for this article to be further copied/distributed or hosted elsewhere without the express permission from Elsevier (WB Saunders). 
and symptoms, and decreasing or alleviating signs and symptoms (Martin, 2005).

Target terms are 75 defined actions or activities that provide further description of the interventions (Martin, 2005). Linking the problem, category, and target terms describes the unique patient- and family-centered actions of the DP clinician in a standardized way. This study mapped text data to structured problem + category + target terms. For example, health care supervision + case management + other community resources describe one intervention. Thus, for a patient with a problem in health care supervision, a discharge planner may provide the patient, parent, or guardian with teaching, guidance, and counseling regarding other community resources.

\subsection{Procedures}

Our institutional review board approved this study. Within the electronic health record, DP staff document their activities using text with a specific note type, which facilitated the identification of their electronic DP documentation. Each clinical note was printed and placed in a binder for coding and review by the study team. Previous studies testing the Omaha System using DP notes demonstrated the feasibility of coding nearly $100 \%$ of text phrases to Omaha System problems and interventions (Bowles, 2000a and Naylor et al., 2000).

\subsection{Data analysis}

Thematic analysis (Vaismoradi, Turunen, \& Bondas, 2013) of the text in each clinical note was conducted to map themes in the text to the Omaha System Categories (problem-intervention-target). The unit of analysis was the phrase that described a patient problem, intervention category, and target. Each note was thoroughly read to capture the context and content followed by extraction of phrases that were imported into an Excel spreadsheet, and mapped to the Omaha System categories (problem-intervention-target) by the study coordinator after extensive training by investigators who had prior research experience mapping text to the Omaha System using thematic analysis. A $10 \%$ random sample of the notes $(n=7)$ was 
NOT THE PUBLISHED VERSION; this is the author's final, peer-reviewed manuscript. The published version may be accessed by following the link in the citation at the bottom of the page.

deidentified and sent to one investigator, who is experienced in the Omaha System and who provided guidance regarding the phrase extraction and mapping phrases to categories approach, interpretation of definitions, and development of decision rules. All authors then reviewed the mapping completed by the study coordinator. Disagreements were discussed by the authors until consensus was reached. Table 1 illustrates how phrases from the DP notes were mapped to the Omaha System.

Table 1. Examples of phrases from clinical notes mapped to the Omaha System.

\begin{tabular}{|c|c|c|c|}
\hline $\begin{array}{l}\text { Phrase from } \\
\text { patient record }\end{array}$ & Problem & Category & Target \\
\hline $\begin{array}{c}\text { "This patient will } \\
\text { leed the following } \\
\text { equipment: } \\
\text { Wheelchair." }\end{array}$ & Health care supervision & Surveillance & Durable medical equipment \\
\hline $\begin{array}{l}\text { "RN will need to } \\
\text { fax any new } \\
\text { prescriptions and } \\
\text { arrange delivery if } \\
\text { needed." }\end{array}$ & Health care supervision & $\begin{array}{l}\text { Case } \\
\text { management }\end{array}$ & $\begin{array}{l}\text { Medication } \\
\text { coordination/ordering }\end{array}$ \\
\hline $\begin{array}{l}\text { "Patient has } \\
\text { health insurance } \\
\text { but the mother } \\
\text { was concerned } \\
\text { about the } \\
\text { coverage of costs } \\
\text { when she returns } \\
\text { home due to } \\
\text { having a different } \\
\text { nsurance carrier." }\end{array}$ & Income & Surveillance & Finances \\
\hline $\begin{array}{l}\text { "It is } \\
\text { recommended } \\
\text { that to assist with } \\
\text { alleviating } \\
\text { patient's anxiety: } \\
\text { allow patient to } \\
\text { either participate } \\
\text { or decline in } \\
\text { discussions re: } \\
\text { plans concerning } \\
\text { dismissal; patient } \\
\text { not be pressured; } \\
\text { positive thinking } \\
\text { approach be } \\
\text { utilized." }\end{array}$ & Mental health & $\begin{array}{l}\text { Teaching, } \\
\text { guidance, } \\
\text { counseling }\end{array}$ & Behavior modification \\
\hline $\begin{array}{l}\text { "Primary } \\
\text { identified }\end{array}$ & Caretaking/Parenting & Surveillance & Support system \\
\hline
\end{tabular}

Applied Nursing Research, Vol 30 (May 2016): pg. 24-28. DOI. This article is (C) Elsevier (WB Saunders) and permission has been granted for this version to appear in e-Publications@Marquette. Elsevier (WB Saunders) does not grant permission for this article to be further copied/distributed or hosted elsewhere without the express permission from Elsevier (WB Saunders). 
NOT THE PUBLISHED VERSION; this is the author's final, peer-reviewed manuscript. The published version may be accessed by following the link in the citation at the bottom of the page.

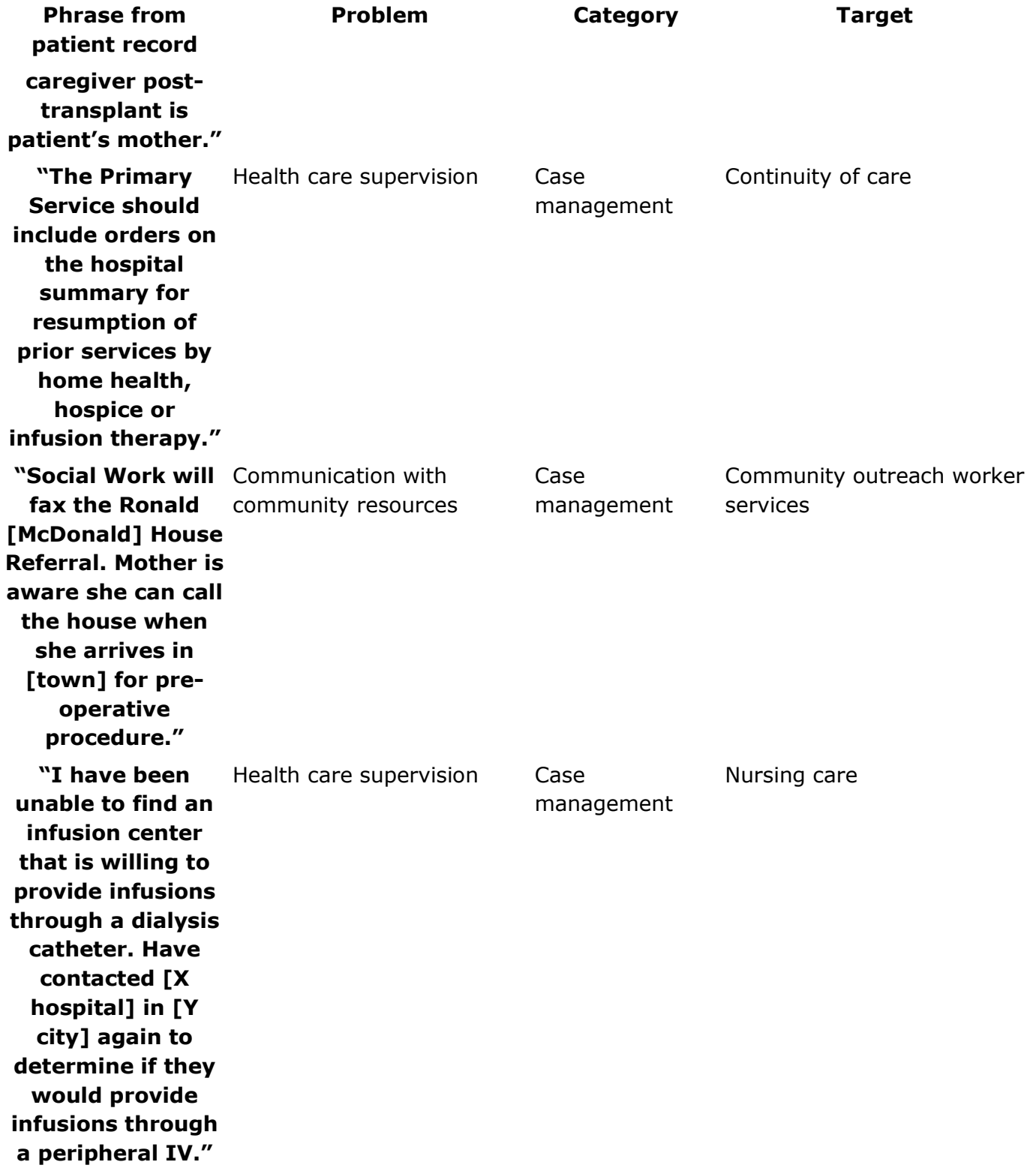

Case

management

Community outreach worker services

$\begin{array}{ll}\text { Health care supervision } & \begin{array}{l}\text { Case } \\ \text { management }\end{array}\end{array}$

Methodological rigor of the qualitative data coding and data analysis was maintained using an audit trail and periodic debriefing among the authors. Reliability was measured via consistency of interpretation and coding of the qualitative data (Graneheim \& Lundman, 2004). An audit trail of process and analytic memos was maintained to support the credibility of the results. Counts and proportions of problems, intervention categories, and targets were calculated. 
Quantitative analyses were performed using the SAS software package (SAS Institute, Inc) to augment the content analysis. Comparisons of problems, intervention categories, and targets between SWs and DPNs were evaluated using $\mathrm{X}^{2}$ and Fisher exact tests. All $p$ values were two-sided, and those $<.05$ were considered statistically significant.

\section{Results}

\subsection{Study patients}

The mean (SD) age of the 28 pediatric patients included in the study was 9 (6.2) years (range, 1 month to 17 years); 13 patients were girls (46\%), and 21 were White (75\%). The mean (SD) length of stay was 11.9 (18.3) days (median, 6.5; range, 2-92 days). Twelve children (48\%) lived with two parents, 10 (40\%) lived in a singleparent household, and three (12\%) lived with adults who were not their parents. Sixteen were admitted for a medical reason (57\%), with a mean (SD) of 2.6 (1.9) chronic conditions (range, $0-8$ ). Half the children $(n=14)$ had public insurance, and $14(50 \%)$ had private hospital insurance. The median number of notes by DP staff per patient was 1 (range, $1-11$ ); 10 patients (36\%) had more than 1 note.

\subsection{Patient problems}

A total of 517 phrases in the notes were mapped to the Omaha System. Eleven of the 42 possible problems in the Omaha System were documented in DP notes. Of these 11 problems, three were in the environmental domain, six were in the psychosocial domain, and two were in the health-related behaviors domain (Table 2). The most frequent problem documented was health care supervision (297/517; $57.4 \%$ ), which was identified as a problem for every patient seen by either an SW or a DPN. No problems were documented in the physiological domain. 
NOT THE PUBLISHED VERSION; this is the author's final, peer-reviewed manuscript. The published version may be accessed by following the link in the citation at the bottom of the page.

Table 2. Patient problems by Omaha System Domain as documented by discharge.

Domain and problem

Environmental

Income

Residence

Sanitation

Psychosocial

Caretaking/Parenting

Communication with community resources

Mental health

Social contact

Growth and development

Interpersonal relationship

Health-related behaviors

Health care supervision

Nutrition

\begin{tabular}{lll}
\multicolumn{3}{c}{ Patients } \\
\hline All $(\mathbf{N}=\mathbf{2 8})^{\mathbf{b}}$ & $\begin{array}{c}\text { Seen by SW } \\
(\mathbf{n}=\mathbf{1 4})\end{array}$ & \multicolumn{1}{c}{$\begin{array}{c}\text { Seen by DPN } \\
(\mathbf{n}=\mathbf{2 0})\end{array}$} \\
$12(43)$ & $11(79)$ & $6(30)$ \\
$6(21)$ & $4(29)$ & $4(20)$ \\
$1(4)$ & $1(7)$ & $0(0)$ \\
$20(71)$ & $13(93)$ & $13(65)$ \\
$11(39)$ & $11(79)$ & $4(20)$ \\
$10(36)$ & $10(71)$ & $4(20)$ \\
$3(11)$ & $3(21)$ & $1(5)$ \\
$2(7)$ & $1(7)$ & $1(5)$ \\
$1(4)$ & $1(7)$ & $0(0)$ \\
$28(100)$ & $14(100)$ & $20(100)$ \\
$2(7)$ & $2(14)$ & $1(5)$
\end{tabular}

Abbreviations: DPN, discharge planning nurse; SW, social worker. avalues are no. of patients (\%).

bSix patients were seen by both an SW and a DPN.

\subsection{Interventions and targets}

Individual interventions, including targets, were recorded and ranged from 2 to 22 per patient. The intervention categories documented by SWs and DPNs were significantly different $\left(X^{2}=29.6\right.$; $p<.001)$. Most phrases documented by DPNs were in the case management intervention category, and the most frequent intervention category documented by SWs was surveillance. No phrases mapped to the treatments and procedures intervention category. The targets used by SWs and DPNs also were significantly different $\left(X^{2}=270.8 ; p<.001\right)$. Of 297 phrases that mapped to the problem home care supervision, 20 unique intervention/target combinations had different targets between SWs' and DPNs' documentation for this problem $\left(X^{2}=150.4 ; p<.001\right.$ ) (Table 3 ). 
NOT THE PUBLISHED VERSION; this is the author's final, peer-reviewed manuscript. The published version may be accessed by following the link in the citation at the bottom of the page.

Table 3. Targets associated with the problem "Health Care Supervision" for SWs and DPNs. $\underline{a}$

Target

Nursing care

Durable medical equipment

Continuity of care

Social work/counseling care

Medical/Dental care

Communication

Medication coordination/ordering

Supplies

Medication administration

Dressing change/wound care

Finances

Community outreach worker services

Respiratory therapy care

Specimen collection

Feeding procedures

Coping skills

Signs/Symptoms-physical

Transportation

Physical therapy care

Occupational therapy care

\begin{tabular}{lll}
\multicolumn{3}{c}{ Phrases } \\
\hline \multicolumn{1}{c}{ By DPNs } & \multicolumn{1}{c}{ By SWs } & \multicolumn{1}{c}{ Total } \\
$\mathbf{( n = 2 0 1 )}$ & \multicolumn{1}{c}{$(\mathbf{n}=\mathbf{9 6})$} & \multicolumn{1}{c}{$(\mathbf{N}=\mathbf{2 9 7})$} \\
$64(31.8)$ & $6(6.3)$ & $70(23.6)$ \\
$52(25.9)$ & $3(3.1)$ & $55(18.5)$ \\
$35(17.4)$ & $11(11.5)$ & $46(15.5)$ \\
$1(0.5)$ & $31(32.3)$ & $32(10.8)$ \\
$11(5.5)$ & $17(17.7)$ & $28(9.4)$ \\
$9(4.5)$ & $5(5.2)$ & $14(4.7)$ \\
$8(4.0)$ & $2(2.1)$ & $10(3.4)$ \\
$6(3.0)$ & $0(0)$ & $6(2.0)$ \\
$3(1.5)$ & $1(1.0)$ & $4(1.3)$ \\
$3(1.5)$ & $0(0)$ & $3(1.0)$ \\
$2(1.0)$ & $6(6.3)$ & $8(2.7)$ \\
$2(1.0)$ & $1(1.0)$ & $3(1.0)$ \\
$2(1.0)$ & $0(0)$ & $2(0.7)$ \\
$2(1.0)$ & $0(0)$ & $2(0.7)$ \\
$1(0.5)$ & $0(0)$ & $1(0.3)$ \\
$0(0)$ & $4(4.2)$ & $4(1.3)$ \\
$0(0)$ & $3(3.1)$ & $3(1.0)$ \\
$0(0)$ & $3(3.1)$ & $3(1.0)$ \\
$0(0)$ & $2(2.1)$ & $2(0.7)$ \\
$0(0)$ & $1(1.0)$ & $1(0.3)$ \\
56 & &
\end{tabular}

Abbreviations: DPN, discharge planning nurse; SW, social worker.

aTargets were significantly different between SWs and DPNs $(X=150.4 ; p<.001)$

bValues are No. of phrases (\%).

Table 4 shows the three most frequently used intervention categories and targets documented by the DP staff. Interventions in the surveillance category were the most frequent overall $(227 / 517$; $43.9 \%)$ and for SWs $(142 / 284 ; 50.0 \%)$. DPNs documented more case management interventions $(129 / 233 ; 55.4 \%)$ than any other category. SWs documented more teaching, guidance, and counseling interventions $(50 / 284 ; 17.6 \%)$ than DPNs $(19 / 233 ; 8.1 \%)$. For all 3 intervention categories (surveillance, case management, and teaching, guidance, and counseling), nursing care and durable medical equipment were the most frequent targets used by DPNs. Social work/counseling care, finances, and coping skills were frequent targets of SW interventions when providing DP care.

Applied Nursing Research, Vol 30 (May 2016): pg. 24-28. DOI. This article is (C) Elsevier (WB Saunders) and permission has been granted for this version to appear in e-Publications@Marquette. Elsevier (WB Saunders) does not grant permission for this article to be further copied/distributed or hosted elsewhere without the express permission from Elsevier (WB Saunders). 
NOT THE PUBLISHED VERSION; this is the author's final, peer-reviewed manuscript. The published version may be accessed by following the link in the citation at the bottom of the page.

Table 4. Most frequent ( $>10 \%$ ) Omaha System targets by intervention category.

\begin{tabular}{|c|c|c|c|c|c|c|}
\hline \multirow[t]{2}{*}{ Provider } & \multicolumn{2}{|c|}{ Surveillance } & \multicolumn{2}{|c|}{$\begin{array}{l}\text { Teaching, guidance, } \\
\text { and counseling }\end{array}$} & \multicolumn{2}{|c|}{ Case management } \\
\hline & Target & No. (\%) & Target & $\begin{array}{l}\text { No. } \\
(\%)\end{array}$ & Target & No. (\%) \\
\hline \multirow[t]{4}{*}{ DPN } & & $(n=85)$ & & $(n=19)$ & & $(n=129)$ \\
\hline & Nursing care & $\begin{array}{l}26 \\
(30.6)\end{array}$ & $\begin{array}{l}\text { Durable medical } \\
\text { equipment }\end{array}$ & $\begin{array}{l}7 \\
(36.8)\end{array}$ & Nursing care & $\begin{array}{l}35 \\
(27.1)\end{array}$ \\
\hline & $\begin{array}{l}\text { Durable medical } \\
\text { equipment }\end{array}$ & $\begin{array}{l}23 \\
(27.1)\end{array}$ & Nursing care & $\begin{array}{l}4 \\
(21.1)\end{array}$ & $\begin{array}{l}\text { Continuity of } \\
\text { care }\end{array}$ & $\begin{array}{l}32 \\
(24.8)\end{array}$ \\
\hline & Support system & $\begin{array}{l}11 \\
(12.9)\end{array}$ & Finances & $\begin{array}{l}4 \\
(21.1)\end{array}$ & $\begin{array}{l}\text { Durable medical } \\
\text { equipment }\end{array}$ & $\begin{array}{l}23 \\
(17.8)\end{array}$ \\
\hline \multirow[t]{5}{*}{ sw } & & $(n=142)$ & & $(n=50)$ & & $(n=92)$ \\
\hline & Finances & $\begin{array}{l}26 \\
(18.3)\end{array}$ & $\begin{array}{l}\text { Social } \\
\text { work/counseling } \\
\text { care }\end{array}$ & $\begin{array}{l}13 \\
(26.0)\end{array}$ & $\begin{array}{l}\text { Social } \\
\text { work/counseling } \\
\text { care }\end{array}$ & $\begin{array}{l}18 \\
(19.6)\end{array}$ \\
\hline & Coping skills & $\begin{array}{l}21 \\
(14.8)\end{array}$ & Finances & $\begin{array}{l}8 \\
(16.0)\end{array}$ & Finances & $\begin{array}{l}13 \\
(14.1)\end{array}$ \\
\hline & $\begin{array}{l}\text { Signs/Symptoms- } \\
\text { mental/Emotional }\end{array}$ & $\begin{array}{l}17 \\
(12.0)\end{array}$ & Coping skills & $\begin{array}{l}8 \\
(16.0)\end{array}$ & $\begin{array}{l}\text { Continuity of } \\
\text { care }\end{array}$ & $\begin{array}{l}10 \\
(10.9)\end{array}$ \\
\hline & $\begin{array}{l}\text { Caretaking/Parenting } \\
\text { skills }\end{array}$ & $\begin{array}{l}15 \\
(10.6)\end{array}$ & & & & \\
\hline
\end{tabular}

Abbreviations: DPN, discharge planning nurse; SW, social worker.

In an exploratory analysis, we documented which individuals (patient, caregiver, or both) were mentioned in phrases as care recipients. Most of the DPNs' phrases were focused on the patient $(176 / 233 ; 75.5 \%)$, whereas most of the SWs' phrases were focused on the caregiver $(158 / 284 ; 55.6 \%)\left(X^{2}=124.6 ; p<.001\right)$. Patient age was not considered in the analysis.

\section{Discussion}

We analyzed the content of interprofessional clinical notes as representations of DP provided by specialized DP personnel (SWs and DPNs) to hospitalized children and their families to assist in the formulating and initial implementation of a discharge plan. We identified patient problems and clinician interventions using a standardized terminology that can easily be used in clinical information systems and patient portals. Although 517 DP interventions were provided, only 11 of a possible 42 Omaha System problems were identified for the 28 patients in the analysis.

Applied Nursing Research, Vol 30 (May 2016): pg. 24-28. DOI. This article is (C) Elsevier (WB Saunders) and permission has been granted for this version to appear in e-Publications@Marquette. Elsevier (WB Saunders) does not grant permission for this article to be further copied/distributed or hosted elsewhere without the express permission from Elsevier (WB Saunders). 
The results of this study begin to inform us about the nature and complexity of DP actions and activities for hospitalized children and their families as they transition from the hospital to home. This knowledge increases our understanding of the contributions by hospital DP personnel to the care of pediatric patients. The documentation reflected a spectrum of patient and family needs during the transition to home.

Although this is, to our knowledge, the first study using data from pediatric patient records, three prior reports have used the Omaha System to describe hospital DP within the context of transitional care for hospitalized adults. In this study, health care supervision was documented as a problem for every patient, which validates the rationale for engaging DP staff to coordinate care in the transition to home-based care services. In contrast, Bowles (2000b) and Naylor et al. (2000) found the most frequent problems to be in the physiological domain. No physiological problems were addressed by DP staff in our study, which may be explained by the division of DP responsibilities across numerous members of the health care team at the study site. Problems within the physiological domain are often addressed by the physician and nurse care team members through treatments and procedure interventions and teaching during the entire course of hospitalization (Lerret, 2009).

Case management and surveillance were the most frequent categories of interventions by DP staff caring for pediatric patients and their families. DPNs provided proportionally (and significantly?) more case management while SW provided more surveillance. This is consistent with our study site, where DP staff were primarily focused on assessing continuing care needs of children with medically complex cases and setting up post-acute care services to address them. The lowest category for both DPN and SW was teaching, guidance, and counseling. This is likely because discharge teaching is often a primary role of the bedside nurse in preparing patients for discharge (Bowles, 2000a, Bowles, 2000b, Kornburger et al., 2013 and Maloney and Weiss, 2008) and, therefore, not a primary focus of DP staff. In contrast, case management was the least frequent category in descriptions of DP in adults (Naylor et al., 2000). This may be due to changes in practice over the past decade or differences between

Applied Nursing Research, Vol 30 (May 2016): pg. 24-28. DOI. This article is (C) Elsevier (WB Saunders) and permission has been granted for this version to appear in e-Publications@Marquette. Elsevier (WB Saunders) does not grant permission for this article to be further copied/distributed or hosted elsewhere without the express permission from Elsevier (WB Saunders). 
populations and settings. Further research is needed to understand differences between DP services across settings and systems.

Not surprising, no treatments and procedures (i.e., providing hands-on care) were included in the repertoire of interventions used by discharge planners in our study. This finding is supported by knowledge of the practice of both SW and DPN at the facility, in which both disciplines plan for the provision of technical activities such as wound care, specimen collection, or exercises at home, versus providing hands-on care themselves. In contrast, in complex care situations that involve an advanced practice nurse (eg, a transplant coordinator) in the continuum of care from inpatient to outpatient services, the DP functions may include medical treatments and procedures, as well as the discharge management responsibilities (Lerret et al., 2014). This was true in the studies of adult patients (Bowles, 2000b, Brooten et al., 2003 and Naylor et al., 2000). Within a DP model of care that includes a prescribed DP role, the design and initial implementation of the discharge plan most likely involves activities such as management, oversight, and supervision, rather than hands-on care. Further research is needed with different DP models.

Targets of interventions in the DP model appeared to reflect differing professional perspectives of the SWs and DPNs. For example, finances, commonly an SW concern, were a focus of SW interventions. In the hospital's DP model, SWs were consulted for situations in which DP needs involved enrollment in waivered programs to pay for services. In contrast, arranging for durable medical equipment was a frequent target of DPNs, which is consistent with DPNs being consulted if transitional DP needs were primarily medically based services. The categorization framework provided by the Omaha System allows for interprofessional documentation that captures both the individual patient complexity and the unique focus of professionals with specific training. Further study is needed to determine whether the difference in targets of DP interventions between the SWs and DPNs was influenced by a difference in training or by the DP model.

The findings indicate the utility of the Omaha System as an organizing framework to capture and systematically codify, at the individual patient level, discharge planner/patient encounter data that link patient problems directly to DP interventions. Further studies are

Applied Nursing Research, Vol 30 (May 2016): pg. 24-28. DOI. This article is (C) Elsevier (WB Saunders) and permission has been granted for this version to appear in e-Publications@Marquette. Elsevier (WB Saunders) does not grant permission for this article to be further copied/distributed or hosted elsewhere without the express permission from Elsevier (WB Saunders). 
needed to compare DP models among various types of complex patients and families.

The three-component documentation of problem, intervention category, and target lends itself to applications in electronic health record environments and maintains the detail needed for understanding the needs of children with complex medical conditions and their families. As electronic applications expand, categorization of process of care notes using standardized terminologies such as the Omaha System can provide both a record of the encounter and a mechanism for analysis of care processes across different segments of the pediatric population.

\subsection{Limitations}

This analysis used data from a small sample of pediatric patients in a single children's hospital at a large academic medical center, although the sample size approximates prior work with mapping patient hospital records to the Omaha System (Bowles, 2000a). The roles of the SWs and DPNs in the DP model of care at our study site may not be generalizable to other centers. These roles may be operationalized differently at other hospitals, may include different role expectations for DP assessment and intervention, and may have different configurations of role responsibilities for DP.

The 28 children in the sample had only 11 of 42 problems in three of a possible four problem domains of the Omaha System. Whether this finding occurred because of the study setting's DP model, the relatively small sample of children and their specific health conditions, or the management of other aspects of discharge preparation by the health care team cannot be determined from this analysis. Nevertheless, the distribution of the problems across the three domains, the number of unique intervention combinations, and hundreds of interventions reaffirm the holistic nature and intricacy of the work involved in addressing DP in pediatric patients with complex care needs.

The results of this study were role centric in that the activities of the SWs and DPNs differed in the provision of DP. Given that most patients had either a DPN or SW, the results may be dependent on the been granted for this version to appear in e-Publications@Marquette. Elsevier (WB Saunders) does not grant permission for this article to be further copied/distributed or hosted elsewhere without the express permission from Elsevier (WB Saunders). 
type of patient assigned to DPNs and SWs. However, it is also possible that DPNs and SWs have different professional approaches to practice that are reflected in different problems being identified and addressed somewhat differently. A patient-centric approach to describing DP actions and activities by combinations of providers such as DPNs and SWs, or any member of the health care team, would most likely capture a broader range of problems and interventions.

\section{Conclusions}

The results of this study highlight the potential utility of standardized terminologies such as the Omaha System for categorizing the DP process in electronic form. Coding the documentation from DP staff using a standardized terminology provides a description of the nature, complexity, and prevalence of problems experienced by hospitalized children as they transition from the hospital to the next setting. Standardized terminologies can then be used to examine the contributions of DP staff to the care transition process. The resulting information can be used to improve care planning, education of DP staff, and perhaps DP models of care used by health care institutions.

Illuminating the patient problems related to continuity of care and interventions of DP is the critical first step in our ability to link problems and interventions with outcomes attributable to the role of the hospital discharge planner. The configuration of the DP model and preparation for pediatric patients and families need further study to determine the optimal model for discharge preparation care services and the delivery of DP care, and to understand the unique role of the discharge planner in the discharge process.

\section{Conflict of interest statement}

The authors report no conflict of interest in the conduct of the study or in the writing of this manuscript.

\section{References}

Berry, Agrawal, et al., 2013. J.G. Berry, R.K. Agrawal, E. Cohen, D.Z. Kuo. The landscape of medical care for children with medical complexity. Children's Hospital Association, Alexandria, VA \& Overland, KS (2013)

Applied Nursing Research, Vol 30 (May 2016): pg. 24-28. DOI. This article is (C) Elsevier (WB Saunders) and permission has been granted for this version to appear in e-Publications@Marquette. Elsevier (WB Saunders) does not grant permission for this article to be further copied/distributed or hosted elsewhere without the express permission from Elsevier (WB Saunders). 
Berry, Toomey, et al., 2013. J.G. Berry, S.L. Toomey, A.M. Zaslavsky, A.K. Jha, M.M. Nakamura, D.J. Klein, ... M.A. Schuster. Pediatric readmission prevalence and variability across hospitals. Journal of the American Medical Association, 309 (4) (2013), pp. 372-380

Bowles, 2000a. K.H. Bowles. Application of the Omaha System in acute care. Research in Nursing \& Health, 23 (2) (2000), pp. 93-105

Bowles, 2000b. K.H. Bowles. Patient problems and nurse interventions during acute care and discharge planning. Journal of Cardiovascular Nursing, 14 (3) (2000), pp. 29-41

Brooten et al., 2003. D. Brooten, J.M. Youngblut, J. Deatrick, M. Naylor, R. York. Patient problems, advanced practice nurse (APN) interventions, time and contacts among five patient groups. Journal of Nursing Scholarship, 35 (1) (2003), pp. 73-79

Gardner et al., 2014. R. Gardner, Q. Li, R.R. Baier, K. Butterfield, E.A. Coleman, S. Bravenstein. Is implementation of the care transitions intervention associated with cost avoidance after hospital discharge? Journal of General Internal Medicine, 29 (6) (2014), pp. 878-884

Graneheim and Lundman, 2004. U.H. Graneheim, B. Lundman. Qualitative content analysis in nursing research: Concepts, procedures and measures to achieve trustworthiness. Nurse Education Today, 24 (2) (2004), pp. 105-112

Hansen et al., 2013. L.O. Hansen, J.L. Greenwald, T. Budnitz, E. Howell, L. Halasyamani, G. Maynard, ... M.V. Williams. Project BOOST: Effectiveness of a multihospital effort to reduce rehospitalization. Journal of Hospital Medicine, 8 (8) (2013), pp. 421-427

Holland and Hemann, 2011. D.E. Holland, M.A. Hemann. Standardizing hospital discharge planning at the Mayo Clinic. Joint Commission Journal on Quality and Patient Safety, 37 (1) (2011), pp. 29-36

Kornburger et al., 2013. C. Kornburger, C. Gibson, S. Sadowski, K. Maletta, C. Klingbell. Using "teach-back" to promote a safe transition from hospital to home: An evidence-based approach to improving the discharge process. Journal of Pediatric Nursing, 28 (3) (2013), pp. 282-291

Lerret, 2009. S.M. Lerret. Discharge readiness: An integrative review focusing on discharge following pediatric hospitalization. Journal for Specialists in Pediatric Nursing, 14 (4) (2009), pp. 245-255

Lerret et al., 2014. S.M. Lerret, M.E. Weiss, G. Stendahl, S. Chapman, K. Neighbors, K. Amsden, ... E.M. Alonso. Transition from hospital to home following pediatric solid organ transplant: Qualitative findings of parent experience. Pediatric Transplantation, 18 (5) (2014), pp. 527537

Applied Nursing Research, Vol 30 (May 2016): pg. 24-28. DOI. This article is (C) Elsevier (WB Saunders) and permission has been granted for this version to appear in e-Publications@Marquette. Elsevier (WB Saunders) does not grant permission for this article to be further copied/distributed or hosted elsewhere without the express permission from Elsevier (WB Saunders). 
Maloney and Weiss, 2008. L.R. Maloney, M.E. Weiss. Patients' perceptions of hospital discharge informational content. Clinical Nursing Research, 17 (3) (2008), pp. 200-219

Martin, 2005. K.S. Martin. The Omaha System: A key to practice, documentation, and information management. (2nd ed.)Elsevier Saunders, St. Louis, MO (2005)

Mitchell et al., 2015. S.E. Mitchell, J. Martin, S. Holmes, L.C. van Deusen, R. Cancino, M. Paasche-Orlow, ... B. Jack. How hospitals reengineer their discharge processes to reduce readmissions. Journal for Healthcare Quality (2015) May 13, (Epub ahead of print, Retrieved from http://journals.Iww.com/jhqonline/toc/publishahead)

Naylor, 2014. M.D. Naylor. Managing the transition from the hospital. Managed Care, 6 (2014), pp. 27-30

Naylor et al., 2000. M.D. Naylor, K.H. Bowles, D. Brooten. Patient problems and advanced practice nurse interventions during transitional care.

Public Health Nursing, 17 (2) (2000), pp. 94-102

Shepperd et al., 2013. S. Shepperd, N.A. Lannin, L.M. Clemson, A. McCluskey, I.D. Cameron, S.L. Barras. Discharge planning from hospital to home. The Cochrane Database of Systematic Reviews, 1 (2013), p. CD000313

Srivastava and Keren, 2013. R. Srivastava, R. Keren. Pediatric readmissions as a hospital quality measure. Journal of the American Medical Association, 309 (4) (2013), pp. 396-398

Vaismoradi et al., 2013. M. Vaismoradi, H. Turunen, T. Bondas. Content analysis and thematic analysis: Implications for conducting a qualitative descriptive study. Nursing and Health Sciences, 15 (2013), pp. 398-405

This study was funded by the Elizabeth $\mathrm{C}$. Bonner fund for pediatric nursing research at Mayo Clinic, and the Department of Nursing, Mayo Clinic Rochester.

Conflict of interest: None.

Corresponding author at: Division of Nursing Research, Mayo Clinic, 200, First St SW, Rochester, MN, 55905. 